\title{
Previsibilidade do tratamento estético com lentes de contato cerâmicas
}

\author{
Predictability of aesthetic treatment with ceramic contact lenses \\ Predicción del tratamiento estético con lentes de contacto cerámicas \\ Adriana Cristina ZAVANELLI ${ }^{1}$ \\ Janaína Lopes CAETANO ${ }^{2}$ \\ Lorrany Candido da SILVA ${ }^{2}$ \\ Ricardo Alexandre ZAVANELLI ${ }^{3}$
}

${ }^{1}$ Prof. Doutora da Disciplina de Prótese Parcial Fixa do Departamento de Materiais Odontológicos e Prótese, Faculdade de Odontologia de Araçatuba FOA, Unesp. Univ. Estadual Paulista, 14801-903 Aracatuba - SP, Brasil ${ }^{2}$ Cirurgião-Dentista, Especialista em Prótese Dentária pelo Instituto Kenedy de Odontologia, IKO, 74125-170 Goiânia- GO, Brasil ${ }^{3}$ Prof. Associado da Disciplina de Prótese Dentária do Departamento de Reabilitação Oral, Faculdade de Odontologia FO, UFG Univ. Federal de Goiás, 74605-020 Goiânia- GO, Brasil

\section{Resumo}

A constante busca por um sorriso estético e agradável culminou no desenvolvimento de técnicas minimamente invasivas e de materiais restauradores que mimetizam a estrutura dentária. Associado a essa evolução da Odontologia, o refinamento dos procedimentos de cimentação adesiva permitiu a confecção de peças restauradoras com espessuras muito delgadas. Assim, podemos destacar o emprego das lentes de contato cerâmicas como opção de tratamento para a reabilitação estética na prática clínica por empregar procedimentos ultraconservadores e mimetizar a naturalidade das estruturas dentárias. Além disso, o planejamento reverso permite a previsibilidade do tratamento tanto para a equipe profissional quanto para o paciente. Dessa forma, o artigo tem por objetivo descrever o planejamento e execução clínica em seu passo a passo das lentes de contato cerâmicas, ressaltando o protocolo de confecção dos preparos, moldagem e cimentação das peças cerâmicas à base de dissilicato de lítio. Ao final, foram cimentadas seis lentes de contato cerâmicas no arco superior para o restabelecimento da estética do sorriso da paciente. Concluiu-se que a aplicação do planejamento reverso associado com a utilização de cerâmicas à base de dissilicato de lítio possibilitou a recuperação funcional e estética do sorriso quando se empregou a técnica de preparos minimamente invasivos de lentes de contato cerâmicas.

Descritores: Estética Dentária; Porcelana Dentária; Facetas Dentárias.

\section{Abstract}

The constant search for an aesthetic and pleasant smile culminated in the development of minimally invasive techniques and restorative materials that mimic tooth structure. Associated with this evolution of dentistry, the refinement of adhesive cementation procedures allowed the making of restorative parts with very thin thickness. Thus, we can highlight the use of ceramic contact lenses as a treatment option for cosmetic rehabilitation in clinical practice by employing ultra-conservative procedures and mimic the naturalness of dental structures. In addition, the reverse planning allows predictability of the treatment both for professional staff and the patient. Thus, the article aims to describe the planning and clinical performance in their step by step the ceramic contact lenses, emphasizing the protocol of preparation, molding and cementation of ceramics based on lithium disilicate. In the end, six were cemented ceramic contact lenses in the upper arch to restore the patient's smile esthetics. It was concluded that the application of reverse planning associated with the use of ceramic-based lithium disilicate possible functional recovery and smile aesthetics when used the minimally invasive preparation technique of ceramic contact lenses.

Descriptors: Esthetics, Dental; Dental Porcelain; Dental Veneers.

\section{Resumen}

La constante búsqueda por una sonrisa estética y agradable culminó en el desarrollo de técnicas mínimamente invasivas y de materiales restauradores que mimetizan la estructura dental. Asociado a esta evolución de la Odontología, el refinamiento de los procedimientos de cementación adhesiva permitió la confección de piezas restauradoras con espesores muy delgados. Así, podemos destacar el empleo de las lentes de contacto cerámicas como opción de tratamiento para la rehabilitación estética en la práctica clínica por emplear procedimientos ultraconservadores y mimetizar la naturalidad de las estructuras dentales. Además, la planificación inversa permite la predicción del tratamiento tanto para el equipo profesional y para el paciente. De esta forma, el artículo tiene por objetivo describir la planificación y ejecución clínica en su paso a paso de las lentes de contacto cerámicas, resaltando el protocolo de confección de los preparos, moldeado y cementación de las piezas cerámicas a base de disilicato de litio. Al final, se cementaron seis lentes de contacto cerámicas en el arco superior para el restablecimiento de la estética de la sonrisa de la paciente. Se concluyó que la aplicación de la planificación inversa asociada con la utilización de cerámicas a base de disilicato de litio posibilitó la recuperación funcional y estética de la sonrisa cuando se empleó la técnica de preparaciones mínimamente invasivas de lentes de contacto cerámicas.

Descriptores: Estética Dental; Porcelana Dental; Coronas con Frente Estético.

\section{INTRODUÇÃO}

A Odontologia restauradora tem buscado cada vez mais aliar resultados altamente estéticos com máxima preservação de estrutura dentária, de modo a empregar os conceitos dos preparos minimamente invasivos associados à cimentação adesiva. Assim, há uma grande procura por tratamentos que culminem em soluções estéticas associadas à longevidade e previsibilidade que os materiais e técnicas restauradoras podem oferecer ${ }^{1}$.

Dentro desse contexto, as lentes de contato são peças cerâmicas delgadas e delicadas (microlâminas), com espessura em torno de $0,3 \mathrm{~mm}$, sendo coladas sobre a estrutura dental sadia, preferencialmente em esmalte ${ }^{2}$. Apesar de serem extremamente frágeis estruturalmente durante a etapa laboratorial, depois de cimentadas passam a ter resistência adesiva suficiente para suportar as forças oclusais $^{3}$. Com essas restaurações, é possível não somente o restabelecimento da estética dental, mas também a reabilitação de guias de oclusão e desoclusão e de pequenas alterações de cor, tamanho, posição e contorno ${ }^{4}$.

Em relação às lentes de contato ou microlâminas, pode-se diferenciá-las pela necessidade de menor desgaste da estrutura dental (preparos minimamente invasivos), espessura mais delgada da peça protética e indicação para alterações dentais de menor magnitude, como a substituição de restaurações antigas de resina composta, presença de dentes conóides ou dentes com diastemas ${ }^{5}$. Já as facetas ou laminados cerâmicos são peças protéticas mais espessas (até $1 \mathrm{~mm}$ de espessura) que requerem maior desgaste da estrutura dental, pois são indicadas aos casos de dentes com alterações de maior magnitude, como a presença de dentes com maiores manchamentos ${ }^{6}$.

As principais cerâmicas indicadas para as lentes de 
contato são as cerâmicas ácido sensíveis à base de feldspato ou de dissilicato de lítio, que podem ser condicionadas com auxílio do ácido fluorídrico e posteriormente "coladas" ou cimentadas com auxílio de cimento resino do tipo fotoativado de forma adesiva na estrutura dentária previamente preparada ${ }^{7}$.

Dessa forma, o emprego das lentes de contato cerâmicas vem mostrando um papel eficiente e de prognóstico clínico positivo, aumentando a procura por esses tratamentos nos consultórios odontológicos ${ }^{8}$. Assim, o objetivo desse artigo foi de descrever o planejamento e execução clínica em seu passo a passo das lentes de contato cerâmicas para uniformizar a cor, melhorar o posicionamento e contorno de dentes anteriores, evidenciando a previsibilidade dos procedimentos.

\section{CASO CLÍNICO}

Paciente L.F., 24 anos, procurou atendimento odontológico no curso de Especialização em Prótese Dentária do Instituto Kenedy de Odontologia - IKO-GO, com o intuito de melhorar a estética do seu sorriso. Como queixa principal, a paciente relatou que estava insatisfeita com as facetas de resina nos dentes anteriores confeccionadas há seis meses, em virtude da instabilidade de cor que as mesmas começaram a apresentar após o tratamento. Após a anamnese, avaliação clínica (extraoral e intraoral) foi constatada a presença de restaurações de resina composta nos dentes 12, 11, 21 e 22, sendo nítida a diferença de cor entre a estrutura dentária e o material restaurador, não transmitindo o aspecto de naturalidade do sorriso (Figuras 1 e 2).

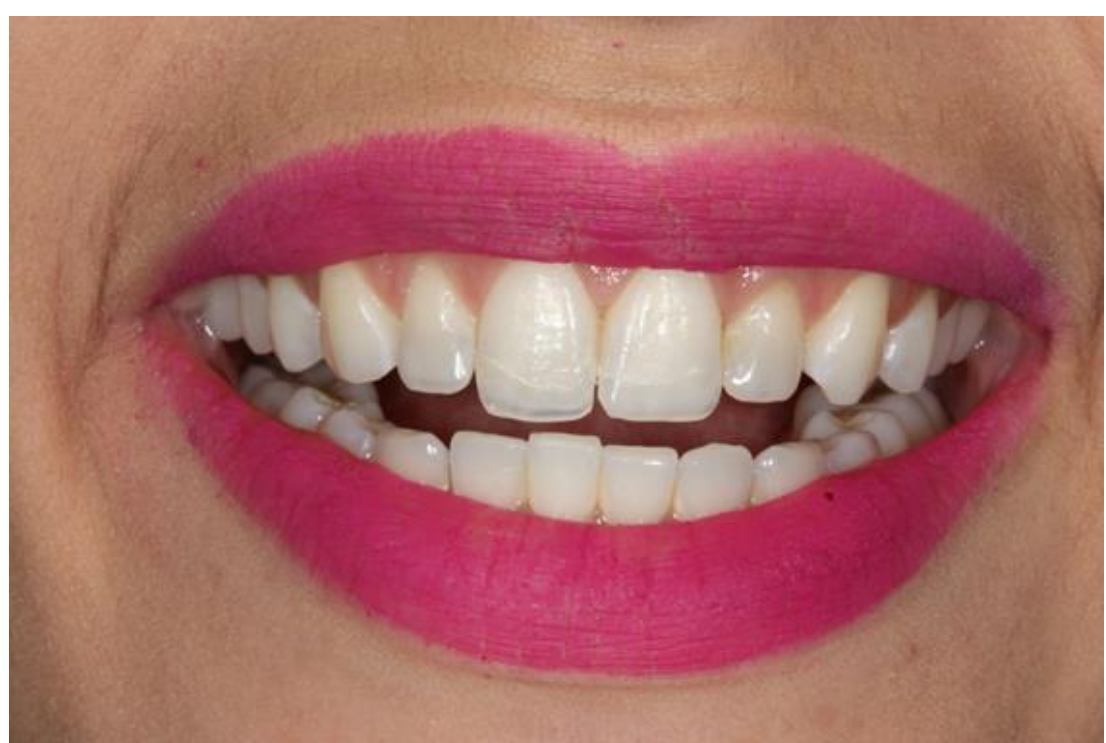

Figura 1: Aspecto extraoral inicial do sorriso da paciente, evidenciando a presença de restaurações de resina composta nas bordas incisais dos dentes $11,12,21$ e 22 .

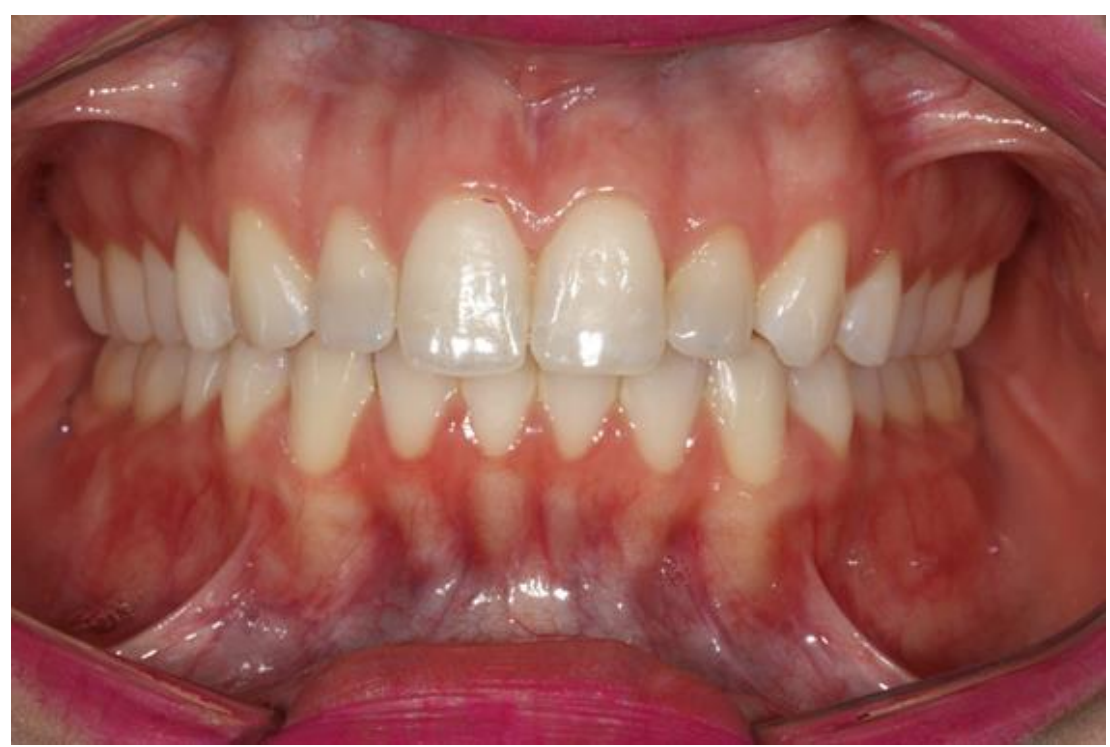

Figura 2: Vista intraoral dos arcos superior e inferior em oclusão, evidenciando restaurações de resina composta insatisfatórias nos incisivos. Nota-se que são restaurações com contorno e coloração deficientes.
Após o relato da paciente com as suas expectativas em relação ao tratamento, fotografias extra e intraorais, foi realizada a moldagem dos arcos superior e inferior para confecção dos modelos de estudo. Ao analisar a expectativa da paciente com a condição clínica apresentada, o tratamento proposto foi a confecção de lentes de contato cerâmicas à base de dissilicato de lítio nos dentes 11, 12, 13, 21,22 e 23 . Como a paciente havia realizado o clareamento de consultório há seis meses, foi acordado entre a equipe e a paciente realizar o clareamento caseiro por 15 dias.

Para melhor previsibilidade da resolução do caso, os modelos de estudo e as fotografias foram enviados ao Laboratório de Prótese e os técnicos realizaram o enceramento de diagnóstico estético, a partir de orientações enviadas sobre as alterações quanto ao tamanho, formato e posição dos dentes (Figura 3).

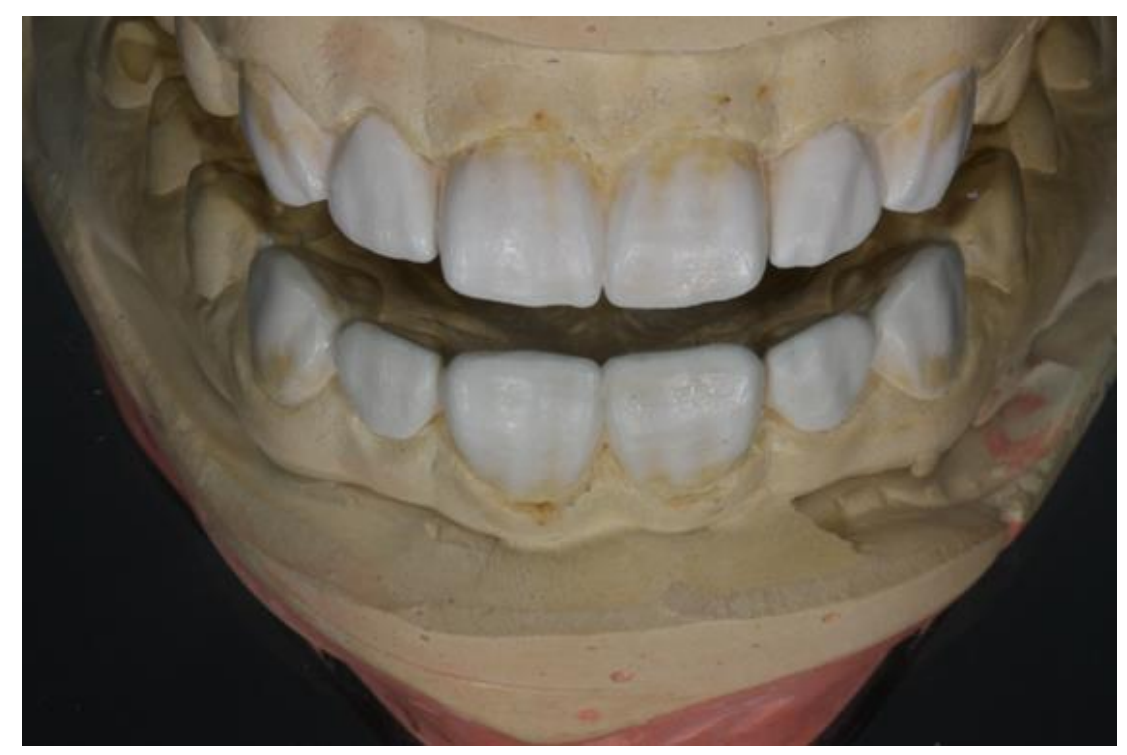

Figura 3: Vista frontal dos modelos de estudo com o enceramento de diagnóstico estético dos elementos 13 ao 23 , que restabeleceu o alinhamento e a forma dos dentes anteriores.

Em seguida, para avaliação preliminar do resultado e aprovação da paciente, foram confeccionadas guias com silicone de condensação laboratorial (Zetalabor, Zermack, Badia Polesine, Itália) e realizado o ensaio-estético ou mock up. O guia foi preenchido por resina bis-acrílica na cor A2 (Structur 2 SC, Voco do Brasil, Porto Alegre-RS, Brasil) e posicionado sobre os dentes ainda sem preparo e mantido em posição até que a polimerização inicial se completasse. Após a remoção do guia de silicone, os procedimentos de acabamento foram realizados com brocas de granulação fina (Ponta diamantada 2135 F e 3118 F, KG Sorensen, CotiaSP, Brasil) e lâmina de bisturi $\mathrm{n}^{\circ} 12$ para a remoção dos excessos cervicais. Em seguida, o polimento foi iniciado com o uso de pontas polidoras na seguinte ordem: pontas para desgaste de resina, pontas para pré-polimento, pontas para brilho e escovas de algodão com pasta para polimento (Dhpro, Paranaguá, Paraná, Brasil) (Figura 4).

Após a finalização desses procedimentos, a paciente aprovou o enceramento estético, autorizando $\mathrm{o}$ planejamento realizado sem nenhuma modificação.

Com o auxílio de guias de silicone confeccionadas no modelo encerado para orientar o desgaste (Figuras 5 e 6), os preparos para lentes de contato foram realizados nos dentes $13,12,11,21,22$ e 23 sem necessidade de intervenção anestésica, já que se tratava de preparos minimamente invasivos. Com a ponta diamantada 2135F (Ponta diamantada 2135 F, KG Sorensen, Cotia-SP, Brasil), foi executado um mínimo de desgaste possível para realizar o aplainamento, correção do eixo de inserção e remoção das restaurações de resina composta, não sendo necessária a confecção de canaletas ou sulcos de orientação. Por último, os procedimentos de acabamento dos preparos foram 
realizados com discos Sof Lex (Pop On, 3M ESPE do Brasil, Sumaré-SP, Brasil), com o intuito de remover os ângulos agudos e uniformizar toda a superfície.

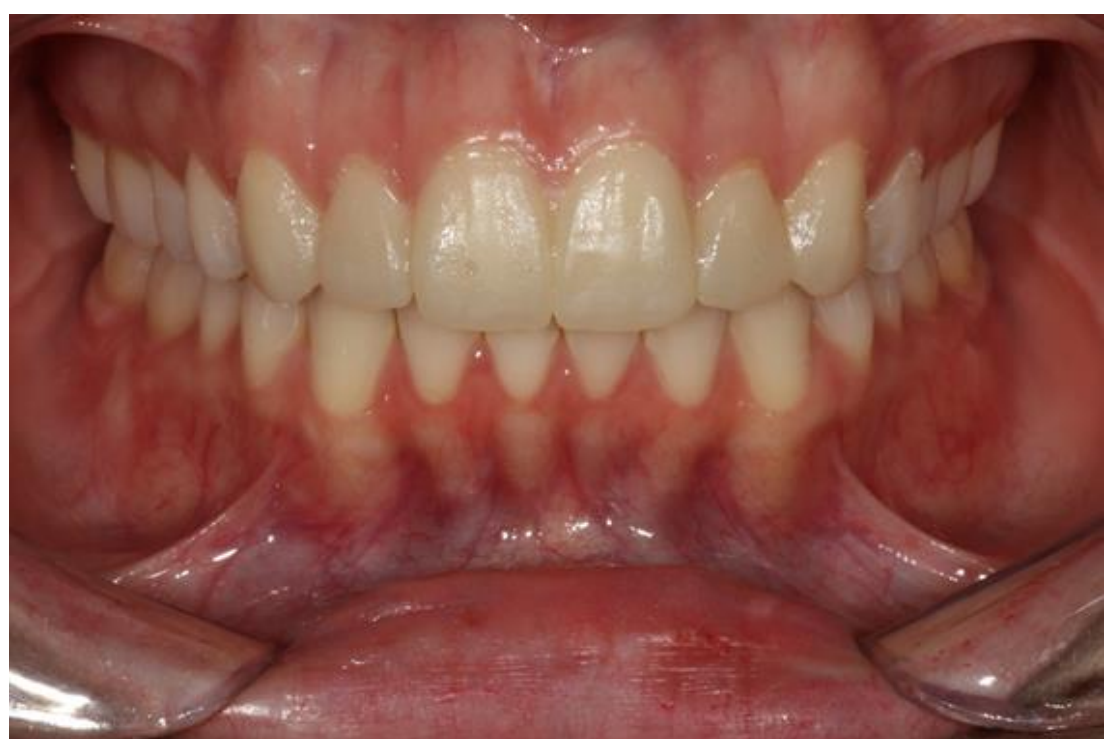

Figura 4: Mock up de resina bis-acrílica em posição, restabelecendo a forma e alinhamento dos dentes anteriores superiores.

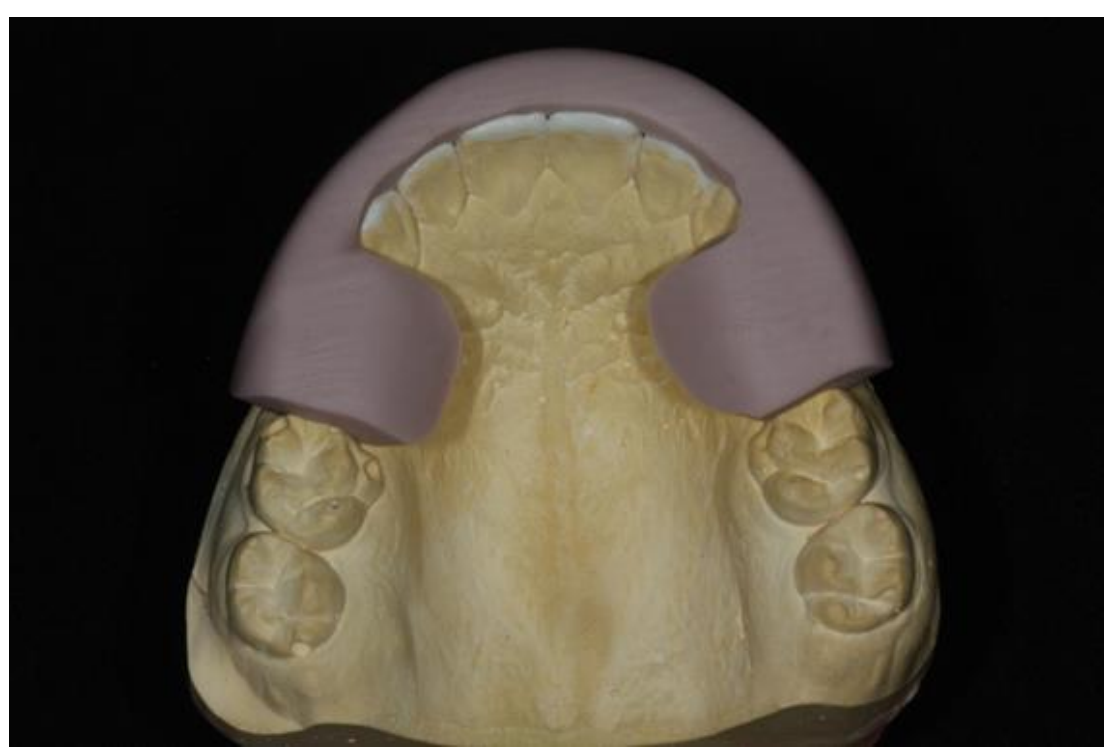

Figura 5: Guias de silicone para orientação dos desgastes vestibulares Notar a perfeita adaptação da guia ao modelo.

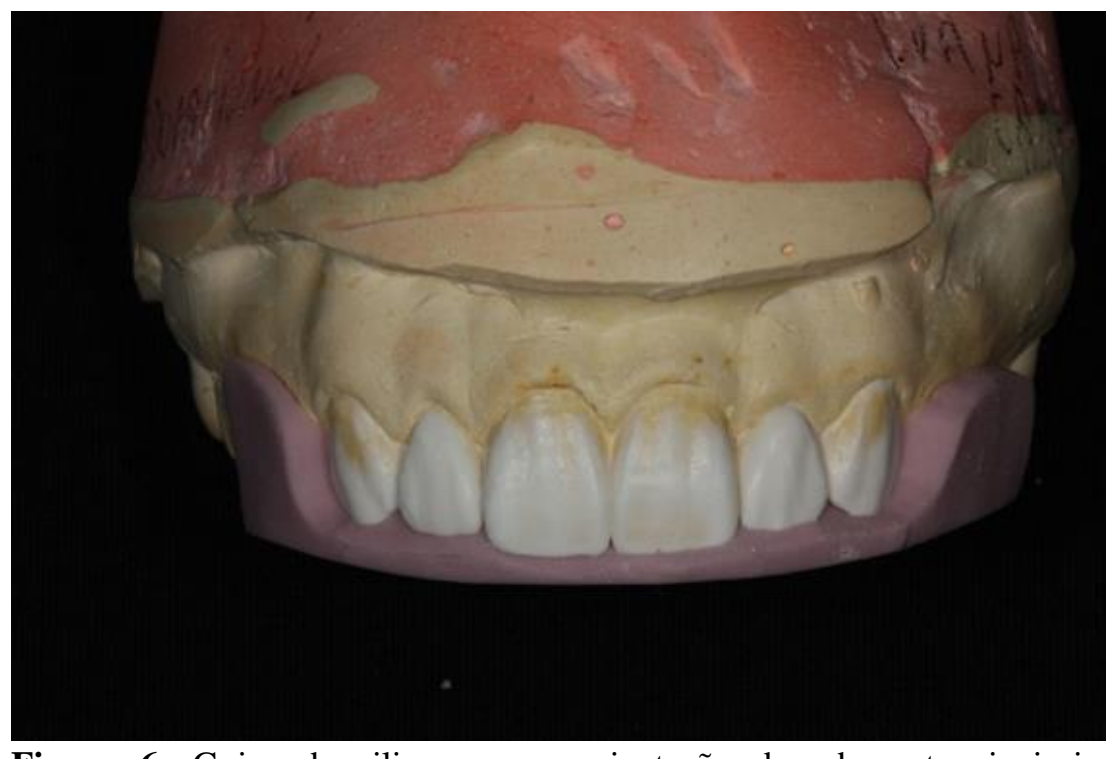

Figura 6: Guias de silicone para orientação dos desgastes incisais. Observar a adaptação da guia nas bordas incisais dos dentes.

A seleção da cor foi orientada pela escala VITA Linearguide 3D-Master (Vita Zahnfabrik, Bad Säckingen, Alemanha), selecionando a cor 1 M1 para as lentes de contato (Figura 7). Em seguida, o afastamento gengival foi executado com fio retrator \#000 (Ultra-Pack, Ultradent) embebido em solução hemostática (ViscoStat Clear, Ultradent) contornando o sulco gengival vestibular dos dentes preparados. Essa técnica proporciona, além do afastamento gengival propriamente dito, isolamento dos fluidos gengivais, auxiliando no procedimento de moldagem para a cópia fiel dos elementos. A técnica de moldagem escolhida foi a de passo único com silicone de adição (Express XT, 3MESPE, Sumaré-SP, Brasil), sendo injetado, após remoção do fio retrator, o material de consistência leve sobre os dentes preparados e, posteriormente, pressionado pelo material de consistência densa. Ao final da polimerização obteve-se molde com reprodução fiel dos elementos preparados, o que permitiu ao protético realizar trabalho de excelência (Figura 8). Após os procedimentos de preparo e moldagem, os provisórios foram confeccionados com resina bisacrílica na cor A1 (Structur 2 SC, Voco do Brasil, Porto Alegre-RS, Brasil). O guia de silicone para enceramento estético foi preenchido com resina bisacrílica e posicionado por 4 minutos sobre os dentes preparados para a polimerização inicial. Após a remoção do guia, os procedimentos de acabamento e polimento foram realizados seguindo as mesmas técnicas utilizadas na confecção do mock up, sem necessidade de realizar cimentação dos provisórios (Figura 9).

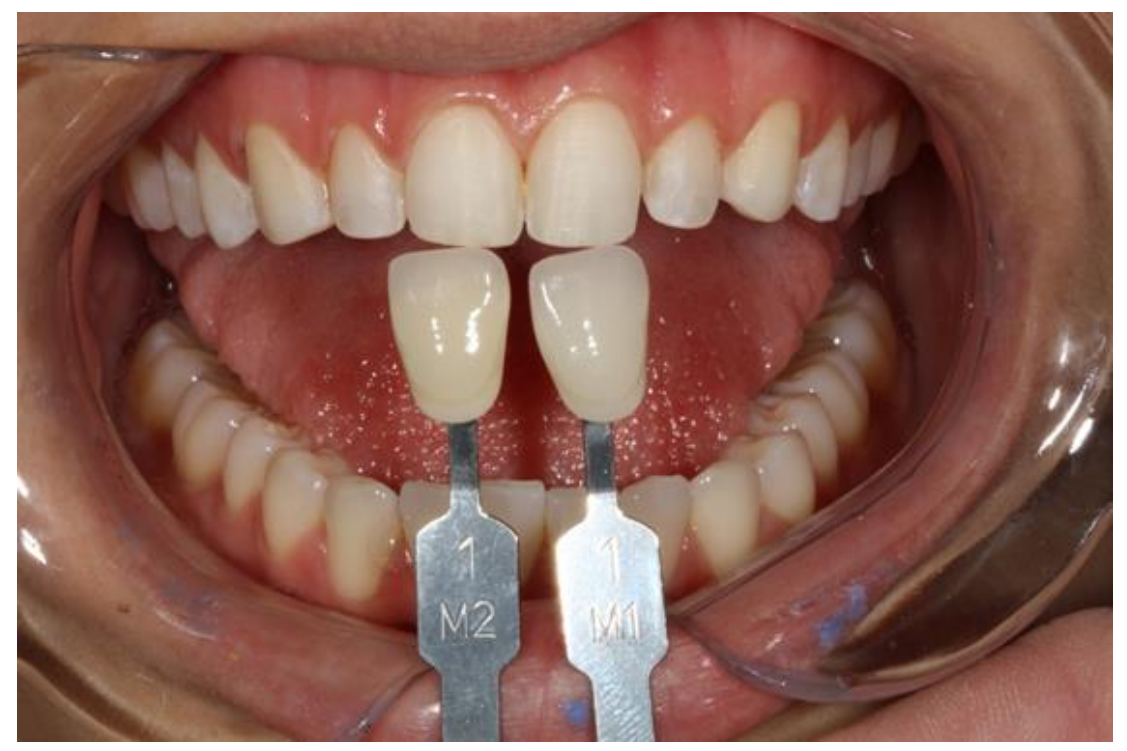

Figura 7: Preparos para lentes de contato realizados nos dentes $13,12,11$, 21, 22 e 23 e seleção da cor com a escala VITA Linearguide 3D-Master.

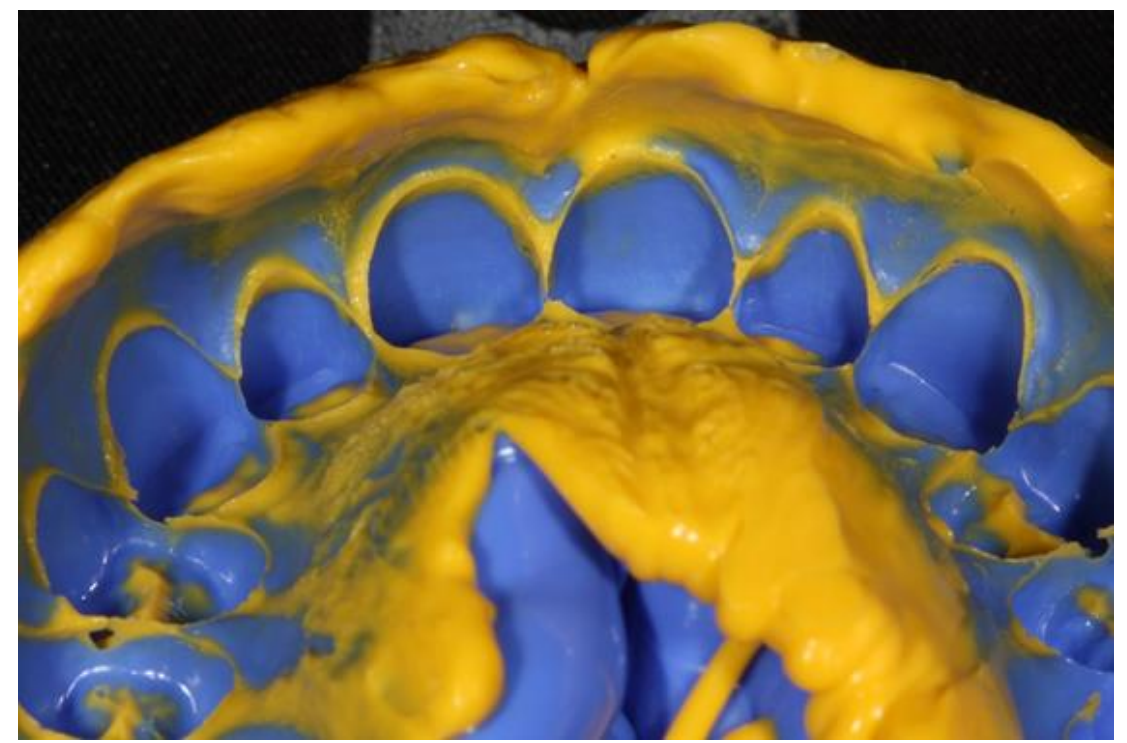

Figura 8: Molde evidenciando a cópia fiel dos elementos preparados.

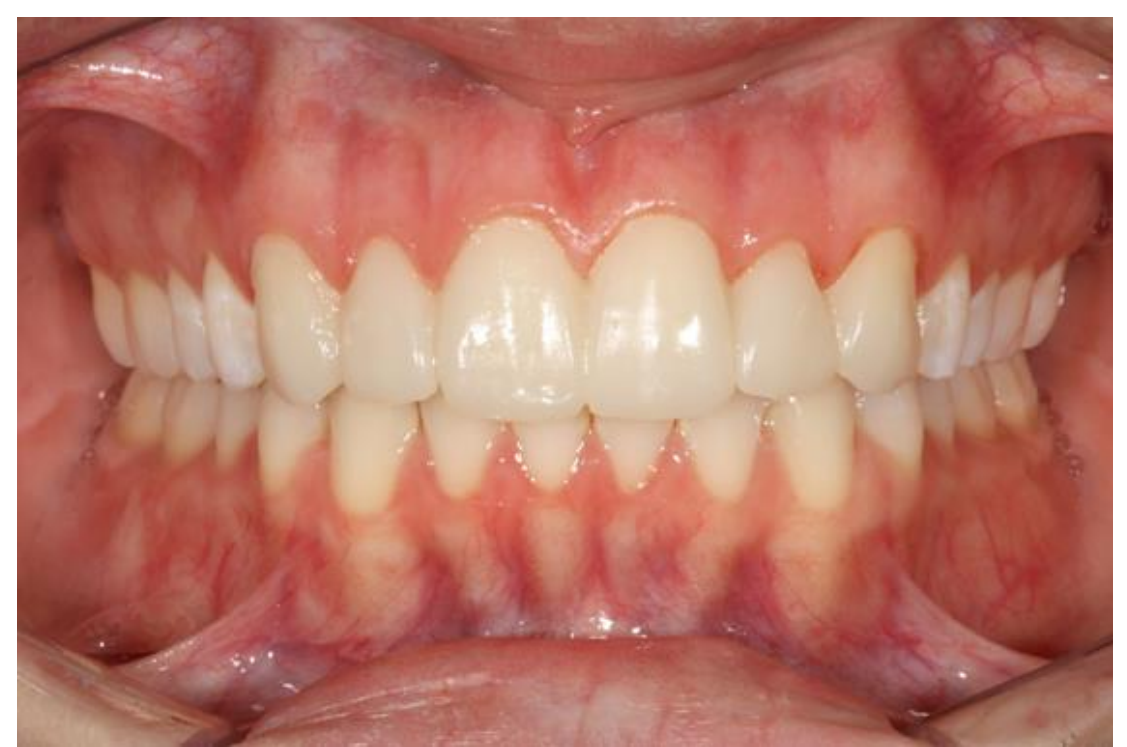

Figura 9: Aspecto intraoral dos provisórios finalizados. Observar a ausência de excessos na região cervical e a lisura alcançada após os procedimentos de acabamento e polimento. 
As peças cerâmicas (Figura 10) foram confeccionadas pelo laboratório com o sistema cerâmico IPS E.max Press (Ivoclar, Vivadent, Barueri, Brasil). No primeiro momento da sessão de cimentação, as peças foram posicionadas no modelo de trabalho para análise quanto à adaptação, presença de excessos ou falta de material e presença de contornos adequados (Figuras 11 e 12).

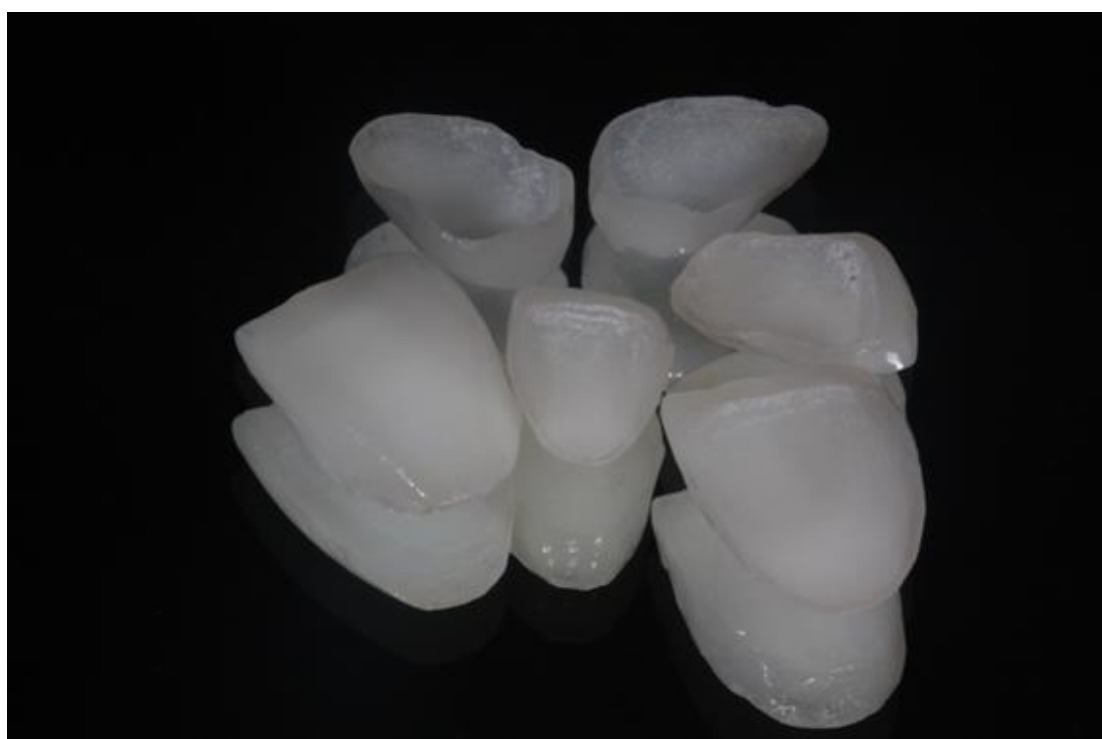

Figura 10: Restaurações cerâmicas IPS E.max Press concluídas antes do início da cimentação. Notar espessura delgada das peças cerâmicas. É necessário cuidado no manuseio das peças na fase pré-cimentação.

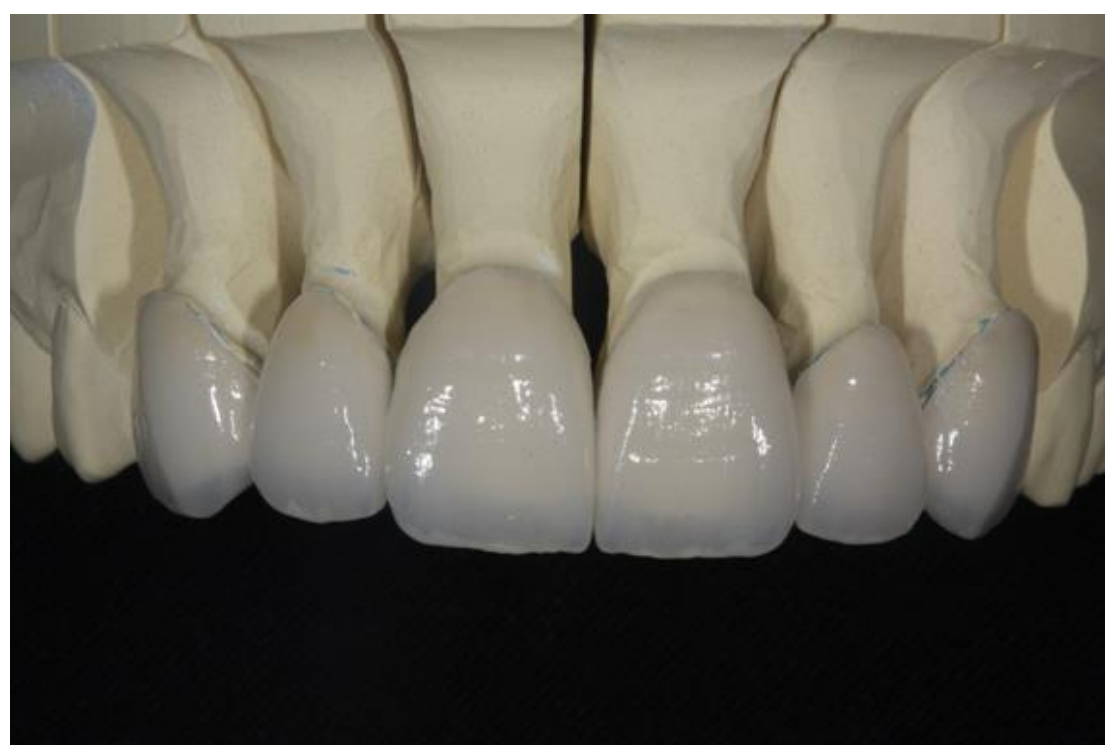

Figura 11: Vista vestibular das peças cerâmicas adaptadas ao modelo de trabalho.

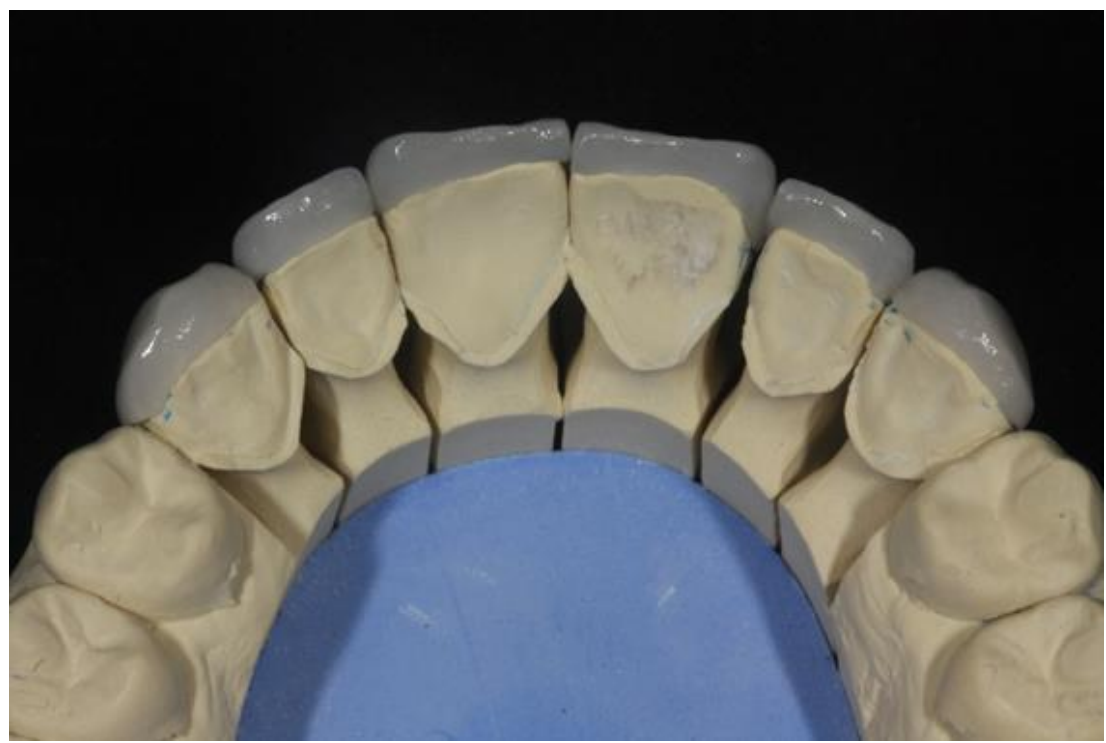

Figura 12: Vista palatina das peças cerâmicas adaptadas ao modelo de trabalho.

Os provisórios foram removidos e os dentes preparados foram limpos com escova de Robson Microtuft (Dhpro, Paranaguá, Paraná, Brasil), pedra-pomes e água. Em seguida, com os preparos secos, realizou a prova seca das lentes de contato para verificar a adaptação e pontos de contatos interproximais. Com o intuito de otimizar o resultado estético das lentes de contato (prova úmida), a seleção da cor do cimento foi realizada através das pastas de prova ou Try in (NX3 Nexus, Kerr Corp., Wallingford, CT,
USA) nas cores transparente e branca. Essas pastas têm o objetivo de auxiliar na seleção do cimento resinoso utilizado, aumentando a previsibilidade do sucesso das lentes de contato.

Após a checagem da adaptação e seleção da cor do cimento na cor transparente, iniciou-se a etapa de cimentação propriamente dita. A superfície interna das peças cerâmicas foi condicionada com ácido fluorídrico a $10 \%$ (FGM Produtos Odontológicos, Joinville, Santa Catarina, Brasil) por 20 segundos e, posteriormente, com ácido fosfórico 37\% (FGM Produtos Odontológicos, Joinville, Santa Catarina, Brasil) por 1 minuto. Em seguida, as peças foram imersas em cuba ultrassônica com água destilada por 5 minutos. Com as peças limpas e secas, o agente silano Monobond N (Ivoclar, Vivadent, Barueri, Brasil) foi aplicado e mantido durante 1 minuto sobre toda a superfície condicionada pelo ácido. A evaporação do solvente ocorreu com jatos de ar quente durante 2 minutos. A sequência de cimentação das lentes foi iniciada pelos incisivos centrais e seguida pelo incisivo lateral e canino do lado direito, finalizando com a mesma sequência do lado esquerdo, sob isolamento absoluto modificado. Após a proteção dos dentes adjacentes com matriz de poliéster, os preparos dentários foram condicionados com ácido fosfórico a 37\% (FGM Produtos Odontológicos, Joinville, Santa Catarina, Brasil) por 30 segundos e, em seguida, lavados e secados abundantemente. Aplicou-se o sistema adesivo (Excite F, Ivoclar, Vivadent, Barueri, Brasil) nos preparos, tendo em vista que não foi realizada a fotopolimerização nesse momento, para que não ocorresse interferência na adaptação das peças.

A seguir, uma camada do cimento fotopolimerizável (NX3 Nexus, Kerr Corp., Wallingford, CT,. USA), na cor previamente selecionada, foi inserida e espalhada na face interna das peças e levadas em posição e pressionadas digitalmente para que ocorresse o extravasamento do cimento ao longo do perímetro da restauração. Os excessos marginais foram removidos com pincel e os excessos proximais com fio dental. Por fim, realizou-se fotoativação por 40 segundos nas faces vestibular, palatina e proximais. Os demais excessos foram removidos com auxílio de lâmina de bisturi $\mathrm{n}^{\mathrm{0}} 12$ e nas regiões proximais foram utilizadas tiras de lixa microcut. $\mathrm{O}$ acabamento e polimento da linha de cimentação das faces vestibular e palatina foram realizados com borrachas abrasivas e pasta de polimento (Dhpro, Paranaguá, Paraná, Brasil). Com auxílio de papel carbono, os guias de lateralidade e protrusão e os contatos cêntricos foram checados e, em seguida, foi realizado polimento rigoroso das regiões ajustadas. O resultado final mostrou ótima integração da estética alcançada com as lentes de contato (Figuras 13 e 14).

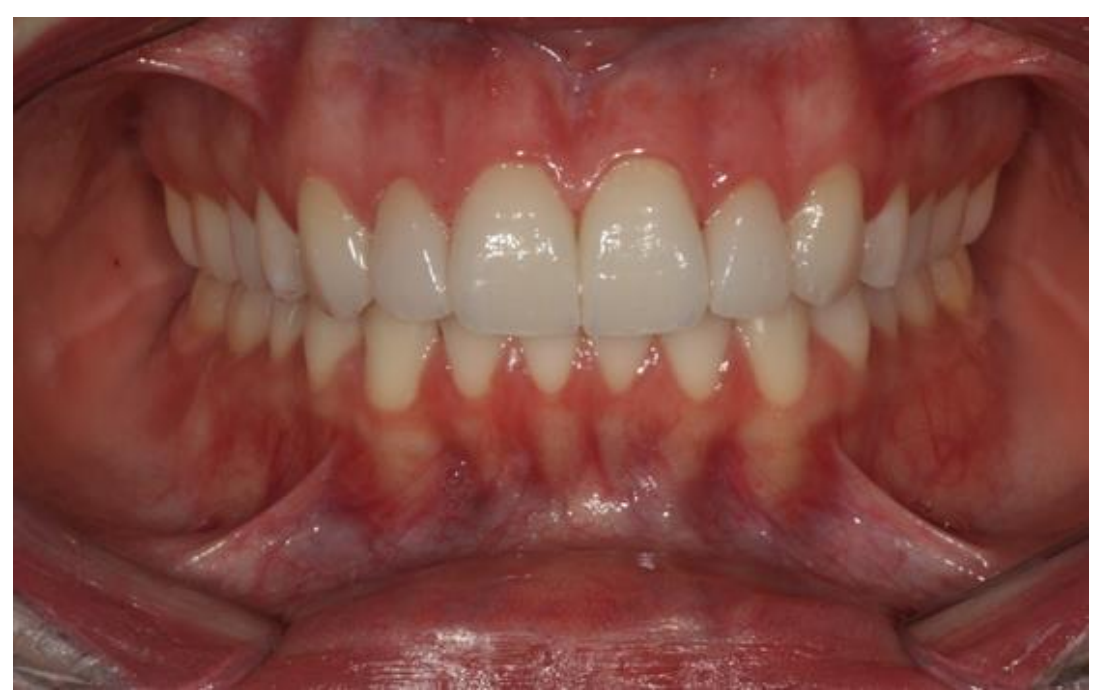

Figura 13: Aspecto final intraoral das peças cimentadas. Observar o restabelecimento da harmonia de forma, alinhamento, textura e cor. 


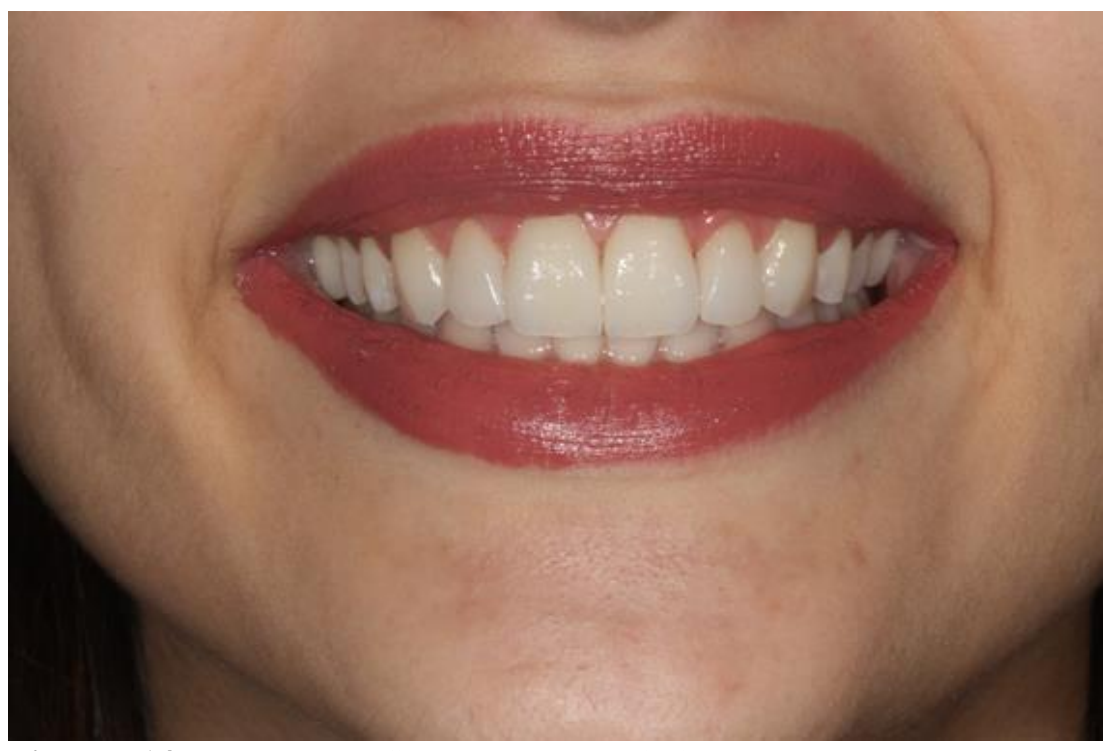

Figura 14: Resultado final do caso clínico executado. Observar a naturalidade alcançada com as lentes de contato cerâmicas, resultando em melhora considerável na estética do sorriso da paciente.

\section{DISCUSSÃO}

Nos últimos anos, a procura por procedimentos estéticos restauradores aumentaram consideravelmente, exigindo o refinamento das técnicas e dos materiais restauradores. Dessa forma, quando o paciente procura por um tratamento reabilitador, ele visa não somente a devolução da parte funcional, mas, sobretudo, a devolução dos padrões estéticos associados com um sorriso harmônico.

Como forma de otimizar o resultado, a equipe de profissionais envolvidas na reabilitação deve realizar o planejamento reverso, após a investigação das queixas primárias e secundárias do paciente em relação ao seu sorriso. A partir desse contato inicial profissional-paciente, os técnicos poderão realizar o enceramento de diagnóstico estético ${ }^{9}$. O ensaio restaurador / mock up no caso clínico proposto permitiu o esclarecimento de dúvidas, a confirmação do diagnóstico e avaliação do planejamento pré-estabelecido. Sem dúvida, é uma ótima ferramenta para mimetizar o resultado estético, motivar o paciente durante o tratamento, avaliar erros e acertos no planejamento e, sobretudo, orientar os preparos durante os desgastes ${ }^{10,11}$.

$\mathrm{O}$ desenvolvimento de materiais odontológicos permite, cada vez mais, a confecção de lentes de contato cerâmicas muito finas $(0,4$ a $0,7 \mathrm{~mm})$ e resistentes quando cimentadas ${ }^{1}$. O material de escolha para a resolução do caso clínico apresentado foi a cerâmica vítrea à base de dissilicato de lítio. Essa cerâmica odontológica apresenta uma matriz vítrea na qual os cristais ficam dispersos de maneira entrelaçada, reduzindo consideravelmente a propagação de trincas no interior do material ${ }^{12}$. Além disso, a sua composição resulta em um índice de refração de luz semelhante ao esmalte dentário, reproduzindo a naturalidade da estrutura dentária. Dessa forma, esse material consegue unir duas propriedades importantes: alta resistência ao desgaste/fratura e boas propriedades ópticas semelhantes ao tecido dentário ${ }^{13}$.

Em relação aos compósitos resinosos, as cerâmicas odontológicas são materiais com melhores propriedades mecânicas e óticas, principalmente quando se discuti estabilidade de cor, alta resistência ao desgaste, menor acúmulo de placa bacteriana, maior resistência mecânica a fratura e longevidade clínica ${ }^{14}$. Assim, quando são indicadas restaurações indiretas, os materiais cerâmicos são as melhores opções para obter sucesso na harmonia estética do sorriso associado com baixas taxas de falhas clínicas ${ }^{15,16}$. No caso clínico relatado, a paciente apresentava facetas de resina nos incisivos centrais e laterais, sem sucesso clínico na estabilidade de cor. Dessa forma, a melhor opção para atingir a estética e a expectativa da paciente foi a confecção de lentes de contato com cerâmicas à base de dissilicato de lítio.

A técnica minimamente invasiva envolve dois aspectos fundamentais: adesão e conservação da estrutura denta $1^{15}$. Como as principais características dos preparos envolvendo essa técnica são expulsividade e falta de retenção, o protocolo da cimentação adesiva deve ser respeitado, seguindo todas as etapas rigorosamente ${ }^{16}$. Além disso, o potencial adesivo das peças cerâmicas pode ser potencializado quando o nível do preparo está sob o esmalte dentário, visto que diversos autores já demonstraram uma maior resistência de união na cimentação envolvendo o esmalte dentário, quando comparado com o substrato de dentina $^{17,18}$. Seguindo esses dois princípios, ao final do procedimento restaurador, a peça cimentada terá uma resistência adesiva suficiente para suportar as forças provenientes dos esforços mastigatórios.

No procedimento clínico proposto, uma adequada cimentação era necessária para obter o sucesso clínico. Assim, foi utilizado um cimento resinoso fotoativado, em virtude da estabilidade de cor que esse material apresenta após a fotopolimerização ${ }^{19,20}$. Os cimentos resinosos quimicamente ativados e de dupla ativação apresentam na sua composição amina terciária como ativador químico, que pode provocar alterações de cor com o tempo ${ }^{8}$.

\section{CONCLUSÃO}

A aplicação do planejamento reverso associado com a utilização de cerâmicas à base de dissilicato de lítio possibilitou a recuperação funcional e estética do sorriso quando se empregou a técnica de preparos minimamente invasivos de lentes de contato cerâmicas, garantindo a previsibilidade do tratamento tanto para a equipe profissional quanto para a paciente. Assim, as lentes de contato cerâmicas permitem solucionar problemas estéticos e funcionais, quando o cirurgião-dentista aplica o seu conhecimento e tem o domínio das técnicas de execução e de planejamento e, sobretudo, rigor na execução criteriosa das etapas clínicas.

\section{REFERÊNCIAS}

1. Bocutti J, Marcondes R. Lentes de contato: uma técnica minimamente invasiva. Rev Dental Press Estét. 2012; 9(2):18-29.

2. Deves C. Avaliação técnica de restaurações cerâmicas minimamente invasivas: Revisão de literatura. Monografia (Curso de especialização em Dentística) Centro de Estudos Odontológico Meridional da Faculdade Meridional. Passo Fundo, RS; 2012. 26p.

3. Teixeira HM, Nascimento ABL, Emerrenciano $M$. Reabilitação da Estética com Facetas Indiretas de Porcelana. J Bras Dent Estét. 2003; 2(7):219-23.

4. Zavanelli AC, Zavanelli RA, Mazaro JVQ, Santos D, Fálcon-Antenucci RM. Tratamento cosmético com lentes de contato e laminados cerâmicos. Arch Health Invest. 2015; 4(3):10-17

5. Soares LM, Soares C. Resultados previsíveis no uso de laminados e fragmentos cerâmicos com preparo minimamente invasivos. Clinica - Int J Braz Dent. 2011; 7(1):36-50.

6. Fuso A, Bottino MA, Faria R. Faceta laminadas: Funcionais, estéticas e preservadoras. Implant News, Editora VM Cultural. 2013; 10(4):34-40.

7. Stoll L, Lopes F. Harmonização do sorriso através de 
laminado cerâmico "lente de contato". Rev. dental press estét. 2009; 6(1):116-24.

8. Aquino APT, Cardoso PC, Rodrigues MB, Takano AE, Porfírio W. Facetas de porcelana: solução estética e funcional. Clínica - Int J Braz Dent. 2009; 5(2):142-52.

9. Bottino MA, Faria R, Valandro LF. Facetas laminadas cerâmicas. In: Bottino MA, Faria R, Valandro LF (eds). Percepção: estética em próteses livres de metal em dentes anteriores e implantes. Artes Médicas; 2009. p. 317-90.

10. Higashi C, Gomes JC, Kina S, Andrade OS, Hirata R. Planejamento estético em dentes anteriores. In: Miyashita, E, Mello, AT. Odontologia estética: planejamento e técnica. Artes Médicas; 2006. p.139-54.

11. Vaz MM, Vaz EC, Alves CBC, Lawder JC, Lenza MA, Souza JB, et al. Utilização do ensaio restaurador como guia de desgaste em reabilitação estética com sistema IPS e.max: caso clínico. Robrac. 2015; 24(68):6-10.

12. Araújo E. Sistema E-max, uma excelente alternativa para recuperação estética do sorriso. Clínica - Int J Braz Dent. 2009; 5(2):126-40.

13. Soares PV, Spini PH, Carvalho VF, Souza PG, Gonzaga $\mathrm{RC}$, Tolentino $\mathrm{AB}$, et al. Esthetic rehabilitation with laminated ceramic veneers reinforced by lithium disilicate. Quintessence Int. 2014; 45(2):129-133.

14. Cardoso PC, Cardoso LC, Decurcio RA, Monteiro LJE. Restabelecimento estético funcional com laminados cerâmicos. Robrac. 2011; 20(52): 88-93.

15. Giray FE, Duzdar L, Oksuz M, Tanboga I. Evaluation of the bond strength of resin cements used to lute ceramics on laser-etched dentin. Photomed Laser Surg. 2014; 32(7):413-21.

16. Soares PV, Zeola LF, Pereira FA, Milito GA, Machado AC. Reabilitação Estética do Sorriso com Facetas Cerâmicas Reforçadas por Dissilicato de Lítio. Robrac. 2012; 21(56):17-28

17. Cardoso MV, Neves A, Mine A, Coutinho E, Van Landuyt $\mathrm{K}$, Munck $\mathbf{J}$ et al. Current aspects on bonding effectiveness and stability in adhesive dentistry. Aust Dent J. 2011; 56(1):31-44.

18. Castelnuovo J, Tjan AH, Phillips K, Nicholls JI, Kois JC. Fracture load and mode of failure ofceramic veneers with different preparations. J Prosthet Dent. 2000; 83(2):171-80.

19. Horn HR. Porcelain laminate veeners bonded to etched enamel. Dent Clin North Am. 1982;27(4): 671-84.

20. Sensi L, Baratieri LN, Monteiro Junior S. Cimentos Resinosos. In: Kina S, Brugrera A. Invisível: Restaurações estéticas cerâmicas. Maringá: Dental Press; 2007. p. 303-19.

\section{CONFLITO DE INTERESSES}

Os autores declaram não haver conflitos de interesse.

\section{AUTOR PARA CORRESPONDÊNCIA}

Ricardo Alexandre Zavanelli

ricardozavanelli@hotmail.com

Submetido em 11/10/2017

Aceito em 09/11/2017 